\title{
$\nabla$
}

\section{Estética e ideologia no cinema de Fritz Lang: as imagens de um poeta moderno entre a arte expressionista e a propaganda nazista*}

\author{
Adriana Schryver Kurtz \\ Universidade Federal Fluminense
}

Restmo: O texto acompanha a trajetória cinematográfica de Fritz

Lang durante os anos pré-hitler: discurindo a ambiguidade ideológica de uma obra clássica como

Metropolis. As relaşoses entre a estética de Lang e a incipiente propagenda nazista são

imlestigadas, no contexto da crise da modernidade que propicion o regime? totalitário nazista.
Abstract: The ted followis the Frit: Lang cinematographic: trajectory during the before-Hitler rears and discusses the ideologic ambiguiry of a chassical work such as Metropolis. The relation between Lang's aesthetics and the incipient Nazi propaganda are investigated in the crisis context of the modernity: that propitiated the nasi otalitarian regime.

\footnotetext{
* Para a minha irmã, Fernanda Kurlz.

** Jornalista, Mestre pelo Programa de Pós-Graduação cm "Comunicução e lnformação "da Faculdade de Biblioteconomia e Comunicação da Universidade Federal do Rio Grande do Sul. Prolessora da Faculdade de Comunicação Social (habilitação em Publicidade c Propaganda) da Escola Superior de Propaganda c Marketing (ESPM- Porto Alegre).
} 
1. Um cineasta de sangue judeu à frente do cinema de Hitler

Alemanha Hitlerista. Década de 30. Joseph Goebbels, Ministro da Propaganda e patrono do cinema alemão, convoca um cineasta de renome e informa-lhe que o Führer deseja vê-lo à frente do cinema do III Reich, realizando filmes nazistas. Goebbels e Hitler teriam visto - e apreciado - uma das obras do diretor: o clássico de ficção científica "Metropolis" (1926). O escolhido é Friedrich Christian Anton Lang (1890-1976); na verdade, Fritz Lang, que acabará emigrando para a França e posteriormente fugindo para os Estados Unidos. Thea von Harbou, roteirista de "Metropolis", esposa e cons160 tante colaboradora dos filmes de Lang (além de entusiástica militante do partido nazista) insiste para que o cineasta aceite o convite. E inútil: em pânico, Lang parte de Berlim no mesmo dia, sem poder retirar do banco suas economias. Thea permanece para servir ao Führer e não reencontrará o marido até sua morte, em 1954.

Não foram certamente motivos estéticos que levaram o Führer e seu Ministro da Propaganda e Ilustração do Povo a desejar Fritz Lang no comando da direção artística da UFA. Tampouco, o fato de "Metropolis" ter sido citado "elogiosamente". "M, o Vampiro de Düsseldorf" (1931) já havia suscitado desconfiança entre os nazistas devido ao título provisório, "Os Assassinos entre nós". Quando atendeu ao chamado de Goebbels, Lang esperava liberar seu último filme, "O Testamento do Dr. Mabuse" (1933), rodado em pleno colapso da República de Weimar, e implacavelmente definido pelo sociólogo Siegfried Kracauer, autor do clássico estudo "De Caligari à Hitler. Uma História Psicológica do Cinema Alemão", como uma espécie de "tribuna de último momento contra o iminente desastre" (1988, p.287-8)

Fritz Lang fugiu e seu filme continuou proibido na Alemanha. Mas a cópia original passou pela fronteira, sendo finalizada e exibida na França, como uma afirmação política do cineasta contra o nazismo. De fato, o criminoso Mabuse professa slogans e doutrinas do III Reich: "É preciso aterrorizar as pessoas até o ponto em que, perdendo a confiança no Estado, elas nos peçam ajuda". E complementa: "A humanidade deve ser lançada num abismo de terror" (apud Sadoul, 1993, p. 231). O sociólogo frankfurtiano resume, de forma impagável, a abordagem ideológica dos filmes de Lang: neles, "a lei triunfa e os fora da lei resplandecem", evidenciando, assim, "o poder do espirito nazista sobre mentes incapazes de evitar seu fascinio peculiar" (Kracauer, 1988, p. 290).

Sobre o episódio com Goebbels, o cineasta recorda: "foi uma experiência extremamente desagradável passar por todos aqueles lon- 
gos corredores (...) protegidos por soldados armados até os dentes" (apud Augusto, 1995, p. 51). Mais desagradável ainda foi, certamente, a confrontação com a verdadeira história de sua família, que Lang procurará, até o fim da vida, ocultar sistematicamente, seja pela omissão de dados e documentos, seja pela "criação" de versões mais nobres: assim o pai, mestre de obras, torna-se arquiteto. A mãe, judia de nascimento procurou integrar-se a uma outra identidade, casandose com um não judeu e convertendo-se, posteriormente, ao catolicismo. Talvez tentando dissuadir Goebbels de sua escolha para o comando do cinema hitlerista, Lang teria dito: "Senhor Ministro, não sei se sabe que minha mãe, que nasceu católica, tinha pais judeus". Ao que Goebbels teria replicado: "Mas, Herr Lang. somos nós que decidimos quem é judeu ou não" ' (apud Sturm, , 1995, p. 92).

O discurso anti-nazista de Fritz Lang tampouco convence o historiador e crítico de cinema Georges Sadoul, que perguntou, cáustico, se a "explicação política de um filme policial de terror" não teria sido "inventada post-facto" (1993, p. 231). Lang disse claramente que "Mabuse" fora uma vingança contra os nazistas, mas é bem provável que seu discurso também tenha respondido a uma crescente pressão mundial contra a Alemanha hitlerista (o diretor, aliás, acabaria transferindo-se para Hollywood, onde teve uma trajetória medíocre). A musa Marlene Dietrich, num mea-culpa inevitável para os cidadãos germânicos que buscaram asilo em países inimigos do IIl Reich, afirmaria numa antológica gravação radiofônica feita nos EUA: "os alemães queriam um Führer e quando esse medonho Hitler surgiu nós dissemos: aí está o nosso Führer".

Vendo "Metropolis" entende-se melhor as restrições de Sadoul. Apesar da beleza e grandiosidade das imagens deste clássico, rodado há mais de 70 anos, a obra tem sido sistematicamente condenada por sua ambiguidade política-ideológica. O filme seria, sobretudo, uma obra-prima fascista, resultado "do casamento entre a estética [a arte de Lang] e a política [a retórica propagandística de Thea] " (Nazário. 1983, p. 43). Já "Os Nibelungos" (1924), também em parceria com Harbou, foi definido por Lang como "um documento nacional destinado a fazer propaganda da cultura alemã em todo o mundo", arrancando de Kracauer um sarcástico comentário: "Sua declaração de algum modo antecipou a propaganda de Goebbels". A grande crítica à este épico germânico recai, invariavelmente, sobre sua concepçāo estética, mas não apenas estética). Segundo Kracauer, os seres humanos são reduzidos à acessórios de cenários monumentais, evidenciando "a onipotência da ditadura" ou o triunfo do ornamental sobre o humano, na qual a autoridade absoluta "se firma ordenando as pes- 
soas sob seu domínio de modo que elas formem agradáveis desenhos". A comparação com a reconhecida eficiência nazista na organização (também ornamental) das massas, é quase automática.

Mas não pensemos em Lang como um caso excepcional dentro da história do cinema expressionista, algum tipo de distorção talvez explicada na franca identificação de Thea com o partido hitlerista. Pelo contrário; sua obra é o exemplo acabado de como um movimento de vanguarda serviu magistralmente (a exemplo do Futurismo italiano) à representação estética do ideário (e da mitologia) nazi-fascista. De fato, este é o ponto nevrálgico em sua análise do expressionismo cinematográfico alemão.

\section{A Vanguarda Maculada}

Como movimento estético nas artes em geral, o Expressionismo desenvolve-se na Alemanha, no período que vai do início da I GG até a eclosão do segundo conflito. No cinema, seu auge coincide com o nascer da República de Weimar ${ }^{2}$, mas a produção total abrange os anos 1919-1930. Em meio aos conturbados acontecimentos do início do século, o movimento expressionista surge "como uma explosão de revolta contra as aparências do mundo e contra o mundo das aparências" (Geada, 1985). A ambiguidade ideológica de "Metropolis", entre outros filmes expressionistas, seria explicado pelo contexto econômico, social, político e estético da época.

O expressionismo cinematográfico circula entre dois extremos claramente opostos que a produção artística da época procura porém, conciliar: por um lado, a necessidade de evasão de uma realidade social demasiado inquietante ; por outro lado, a projecção no exterior de uma ideologia do desespero, tão subjectiva como colectiva (...) De comum [o expressionismo no cinema e na arte alemã], a recusa de qualquer pendor realista e das formas de análise racionalista, o culto das emoções violentas retomado da tradição romântica, o gosto pela desmesura e pela provocação, uma certa sobranceria em relação às massas, a inclinação pelo demoníaco, pelo erotismo e pelo fantástico, e a obsessão da morte (Geada, 1985, p. 14).

O cinema não deixaria de expressar tamanha efervescência ${ }^{3}$. Se mesmo as obras primas do expressionismo foram maculadas pelo ideário nazi-fascista, houve uma cinematografia essencialmente propagandística cujo pior e o "melhor" permanecem impressionantes. Nunca será demais lembrar que este acervo traz em si as marcas da atenção e do tratamento dedicado ao cinema por Hitler e Goebbels.

O Führer, para quem a arte encarnava a nobre função de "obrigar ao fanatismo", é sempre lembrado pela sua ausência dos fronts de 
batalha, falta talvez compensada pelo hábito de assistir a um filme de propaganda de guerra todas as noites. Já Goebbels, que tinhal a fama de desprezar o cinema, cumpria com rigor seu papel de patrono da "sétima arte": passava em revista títulos já liberados pelo intendente de cinema, cortava trechos, remontava, aprovava e desilprovava, além de propor a realização de obras fílmicas relevantes para os interesses do Reich. O mentor da política cultural da Alemanha hitlerista foi um expert em promover mudanças extremas nos filtos históricos das cinebiografias que encomendava para a difusão do "espírito alemão".

Em 1935, Goebbels define sete metas para o cinema nazista, que incluíam a busca de uma linguagem especificamente cinematográfica (embora o cinema alemão já dominasse este campo), o fỉm de "esteticismos" (leia-se expressionismo) e "vulgaridades" (provavelmente o cinema realista). A arte cinematográfica sob o IIl Reich haveria de ser "leal e natural sem patologias e abstrações" (Nazário. 1983:48). Tais providências denotam a extrema importância do cinema para o regime do Führer. A Alemanha nazista chegou a ter 5.446 salas de exibição, a nazificação escolar contou intensivamente com o uso de filmes ideológicos e, mundialmente, a produção fílmica nacional foi apenas superada pela norte-americana.

Mesmo o ponto alto da produção propagandística do Reich - o cinema virtuoso de Leni Riefenstahl - convergiria com a obra ficcional de Fritz Lang: Kracauer sustenta que o "O Trimifo da Vontade" (1934), o maior clássico entre os filmes de sustentação ideológica de regimes totalitários, abordando de forma mítica o Congresso do Partido nazista em Nuremberg, é diretamente inspirado por "Os Nibelungos" e sua estética de ornamentos de massa. Na época, a jovem diretora contou com orçamento ilimitado, uma equipe de 120 pessoas e mais de 30 câmaras, para criar um "universo artificial que parece absolutamente real", resultando num "documentário autêntico relatando um acontecimento complctamente encenado". Um milhão de figurantes, número superior a muitis superproduções do cinema, foi mobilizado para o evento. (Virilio. 1993, p. 129).

\section{Campos de Batalha e de Percepção}

A extrema instrumentalização do cinema na estética e no ideário dos regimes totalitários, bem como na representação imagétical de conflitos bélicos seria muito mais do que um fato circunstancial. $O$ desenvolvimento das técnicas de registro de imagens em movimento e da própria indústria do cinema, segundo a tese de Paul Virilio em 
"Guerra e Cinema", está intimamente relacionada com os avanços tecnológicos e bélicos adquiridos em sucessivos conflitos nacionais e mundiais, chegando ao seu ápice com a I Grande Guerra. A partir de então, a observação e a fotografia aéreas foram as mais importantes fontes de informação para os exércitos. Uma produção que "graças à divisão do trabalho e à produção intensiva de imagens" nada devia ao ritmo de trabalho de uma fábrica. "A fotografia deixa de ser episódica e, mais do que a imagem, trata-se agora de um fluxo de imagens que entra em consonância com as tendências estatísticas do primeiro conflito militar-industrial" (Virilio, 1993, p. 39).

164 Assim, a fotografia perderia drasticamente sua relação com a pintura e com a inspiração pictorial, fenômeno também analisado por Walter Benjamin, no início dos anos 30, em sua "Pequena História da Fotografia" (1985, ps. 91-107). Segundo o filósofo - que, todavia, acreditou que a técnica iria banir a aura da obra de arte - o declínio da fotografia começará exatamente dez anos após sua descoberta: "Ora este é o decênio que precede a sua industrialização" (Benjamin, 1985, p. 91). Entretanto, será refletindo acerca do papel do narrador, que a sensível imagem concebida pelo filósofo frankfurtiano converge, fortemente, com as colocações de Virilio sobre a radical mudança na percepção humana decorrente dos efeitos tecnológicos da guerra - que serão "herdados" pelo cinema:

Uma geração que àinda fora à escola num bonde puxado por cavalos se encontrou ao ar livre numa paisagem em que nada permanecera inalterado, exceto as nuvens, e debaixo delas, num campo de forças de torrentes e explosões, o frágil e minúsculo corpo humano (Benjamin, 1985, p. 198).

"O campo de batalha é um campo de percepção" e os avanços obtidos com a velocidade progressiva dos aparelhos e seu crescente poder de fogo tornam comparáveis, no moderno guerreiro, os atos de disparar uma câmara fotográfica e acionar uma arma. A "violenta violação cinemática do continuum espacial", deflagrada pela arma aérea, passa a engendrar a heterogeneidade dos campos de percepção. "A metáfora da explosão é então correntemente empregada tanto na arte quanto na política". Os cineastas que acompanharam estas mudanças nos fronts da IGG, evoluíram continuamente "do campo de batalha à produção de cine-jornais e, mais tarde, para os filmes de arte" (Virilio, 1993, p. 37). Assim, mais do que a própria técnica industrial de produção dos filmes, as formas de percepção ligadas à realização (os cineastas) e recepção do cinema (as massas) assimilaram este tipo de aprendizado.

Talvez a inserção de Lang, Harbou e mesmo de Riefenstahl, entre 
dezenas de outros criadores que se envolveram na produção de filmes ideológicos, de guerra ou sobre a guerra (Griffith, Buñuel, Dziga Vertov, Chaplin, Eisenstein, Jean Renoir), tenha sido um tributo inevitável ao nascimento do próprio "medium" que, como defende Virilio, fez-se em íntima interdependência com a(s) indústria(s) da guerra. Ou talvez, basta que se faça um trabalho competente - dentro de uma estrutura instrumentalizada de produção - parat realizar um inquestionável cinema de propaganda ou uma obra comprometida com doutrinas totalitárias, conforme salientou Nazário à respeito de Veidt Harlan, diretor do famigerado "O Judeu Süss".

\section{Fritz Lang. Cineasta da Modernidade?}

Em 1947, sob o impacto da barbárie nazi-fascista, Adorno e Horkheimer conceberam uma das mais contundentes críticas à razão iluminista. Em "A Dialética do Esclarecimento" (1985), os teóricos frankfurtianos demonstravam como o pensamento esclarecido acabara convertendo-se em mito, numa clara opção da sociedade burguesa pela dimensão instrumental da razão iluminista, em detrimento de sua potencialidade emancipatória. Tais contradições atravessaram com a mesma intensidade a modernidade e suas expressões artísticas e estéticas, quase sempre indistintas sob a denominação genérica de modernismo. As imagens de "destruição criativa" e "criação destrutiva" foram inseparáveis, diz David Harvey, da implementação da modernidade; e aplicaram-se, de fato, tanto à arte (gerando uma profusão de modas estéticas como o impressionismo, cubismo, fauvismo, dadaísmo, surrealismo, expressionismo) quanto ao espírito empreendedor do progresso e desenvolvimento capitalista. Assim a II Grande Guerra foi o maior evento da "história da destruição criativa do capitalismo". (Harvey, 1994, 21-44),

Âs vésperas do primeiro conflito mundial, lembra ainda David Harvey, o modernismo (rigorosamente "aurático") identificava-se com o espírito democratizador e o universalismo progressista. No período entre guerras, os artistas foram cada vez mais forçados a explicitar seus compromissos políticos, e o trauma da guerra tornara crucial "a busca de um mito apropriado à modernidade". Daí para a sedução de um mito eterno e a construção de "pontes metafóricas entre mitos antigos e modernos", foi um passo. A racionalidade incorporada na máquina, o poder da tecnologia e a cidade como máquina viva foram algumas das imagens adotadas pelos criadores, enquanto outra ala promovia uma arte politicamente comprometida com o proletariado (surrealistas, construtivistas e os artistas-militantes do realismo socialista). Cresciam, entretanto, as adesões à tendências nazi-fascitas ${ }^{4}$. 
O chamado modernismo heróico do entre-guerras assumiu uma forte tendência positivista. Mas o desastre tem, para o autor, uma explicação mais objetiva. Era impossível "inventar mitos que tivessem o poder de superar a política de classe" (Sorel apud Harvey, 1994, p. 41). Assim, a estetização da política, através da produção "destes mitos todo-abrangentes" foi o lado trágico do projeto modernista. Uma forma virulenta de modernismo reacionário acabaria por triunfar na Alemanha Nazista.

"Como a Alemanha concretizou o que havia sido antecipado por seu cinema desde seus primórdios, importantes personagens cinematográficos se tornaram verdadeiros (...) Homunculus apareceram em carne e osso. Autonomeados Caligaris hipnotizaram inumeráveis Cesares, levando-os ao assassinato ${ }^{5}$. Raivosos Mabuses cometeram fantásticos crimes impunemente. (...) Em Nuremberg, o padrão ornamental de Os Nibelungos apareceu numa escala gigantesca: um oceano de bandeiras e pessoas artisticamente arrumadas. As almas foram completamente manipuladas a fim de criar a impressão de que o coração mediava entre o cérebro e as mãos" (Kracauer, 1988, p. 314).

A cinematografia de Fritz Lang - como a de outros grandes nomes da época - tem colocado, em trincheiras opostas, críticos implacáveis e defensores ardorosos. Mas, para além dessa particular discussão, a propaganda nazista e antes dela, obras cinematográficas da vanguarda, maculadas em sua estética e sua concepção política e ideológica, permanecem como registros do ideário (nazi)fascista: impregnados nas imagens, nas narrativas, nos artistas populares e mesmo nas tomadas "documentais" e cenas "reais".

Estes documentos de nossa modernidade ficaram gravados, sobretudo, no imaginário coletivo das massas (para as quais o cinema nasceria), em especial do povo judeu e alemão. Algumas vozes, de qualquer forma, já não se farão ouvir. É crucial a atenção de Sadoul na crítica (também) cinematográfica que dedicou a controvertida obra: "Enfim, os deportados que construiam em Mauthausen, em 1943, uma gigantesca escadaria, diziam naquele campo da morte: Parece Metropolis".

\section{Notas}

1 A frase literal seria de Lang, em entrevista com Armand Panigel (publicada em 1977). Já a resposta de Goebbels é atribuída, oficialmente a Karl Lueger, prefeito anti-semita de Viena entre 1897 e 1910, cidade onde Pauline Schlesinger, mãe de Lang, irá viver - 
convertendo-se ao cristianismo e mudando seu nome para Paula, até casar-se com Anton Lang (Sturm, 1995. p. 92-100).

2 Weimar, berço da "primeira cultura realmente moderna a florescer em nosso século" (Schilling, 1988, p. 17-8) marcou a história deste século com sua riqueza cultural e intelectual, dois quais o Expressionismo, a "Escola de Frankfurt" e a Bauhaus, Gropius, Brecht, Einstein, Paul Klee, Thomas Mann, Kafka, Heidegger sĩo apenas alguns dos exemplos.

3 Hitler, que como nenhuma outra personagem deste século evidenciou a inevitável intersecção entre a arte. as mídias, a política e a propaganda, tinha também suas teorias sobre o valor social da cultura. Em 1938, ao observar multidões que lotavam a sala de um cinema, ele afirmaria: "As massas precisam de ilusão, não somente no teatro ou no cinema, mas também nas coisas sérias da vida" (apud Virilio, 1993, p. 127).

4 Os futuristas italianos e artistas como De Chirico e Ezra Pound identificaram-se, direta ou indiretamente com o regime de Mussolini; Heidegger explicitou sua lealdade aos princípios do nazismo (enraizamento no lugar e tradições) e as "práticas dos projetos do Bauhaus" acabaram sendo utilizadas na construção de campos de concentração. In: Harvey (1994).

5 "O Gabinete do Dr. Caligari" (1914), de Robert Wiene, obra máxima do expressionismo alemão, foi concebido como uma denúncia contra as instituições de poder da época. Censurado pelos produtores e alterado por Lang e Wiene, o filme acabaria transformando-se numa obra "conformista". Caligari é um hipnotizador do parque de diversões, que utiliza o sonâmbulo Cesare para cometer crimes bárbaros.

\section{Bibliografia}

BENJAMIN, Walter. Pequena História da Fotografia. In: Obras escolhidas. Magia e Técnica, Arte e Política. São Paulo: Editora Brasiliense, 1985.

O narrador. Considerações sobre a obra de Nikolai Leskov. In: Obras escolhidas. Magia e Técnica, Arte e Política. São Paulo: Editora Brasiliense, 1985.

GEADA, Eduardo. O Poder do Cinema. Lisboa: Livros Horizonte, 1985 
HARVEY, David. Condição pós-moderna. Uma Pesquisa sobre as Origens da Mudança Cultural. São Paulo: Edições Loyola, 1994.

KRACAUER, Siegfried. De Caligari a Hitler. Uma História Psicológica do Cinema Alemão. Rio de Janeiro: Jorge Zahar Editor Ltada., 1988.

NAZÁRIO, Luís. De Caligari a Lili Marlene: cinema alemão. São Paulo: Global Editora, 1983.

SADOUL, Georges. Dicionário de Filmes. Porto Alegre: L\&PM, 1993.

SCHILLING, Voltaire. O Nazismo: breve história ilustrada. MEC/ SEsu/PROEDI, 1988.

STURM, Georges. Fritz Lang. Uma Ascendência Vienense. In: Revista Imagens. Cinema 100 anos. n. 5, agosto/dezembro de 1995. p. 92-100.

VIRILIO, Paul. Guerra e Cinema. São Paulo: Editora Página Aberta, 1993.

Palavras-chave:

1. expressionismo alemão,

2. cinema,

3. Fritz Lang,

4. nazismo,

5. Metropolis 